\title{
Potential for Plastics to Transport Hydrophobic Contaminants
}

Emma L. Teuten ${ }^{1 *}$, Steven J. Rowland ${ }^{2}$, Tamara S. Galloway ${ }^{1}$, Richard C. Thompson ${ }^{1}$

\section{Supplemental Information}

Included in the Supplemental Information are an expanded version of Figure 1 showing the predicted tissue phenanthrene concentration in A. marina for $0-500 \mathrm{ppm}$ of plastic in the sediment (Figure S1), the sorption isotherm and desorption kinetics for phenanthrene and polyethylene (Figure S2) and further details about the mathematical modelling.

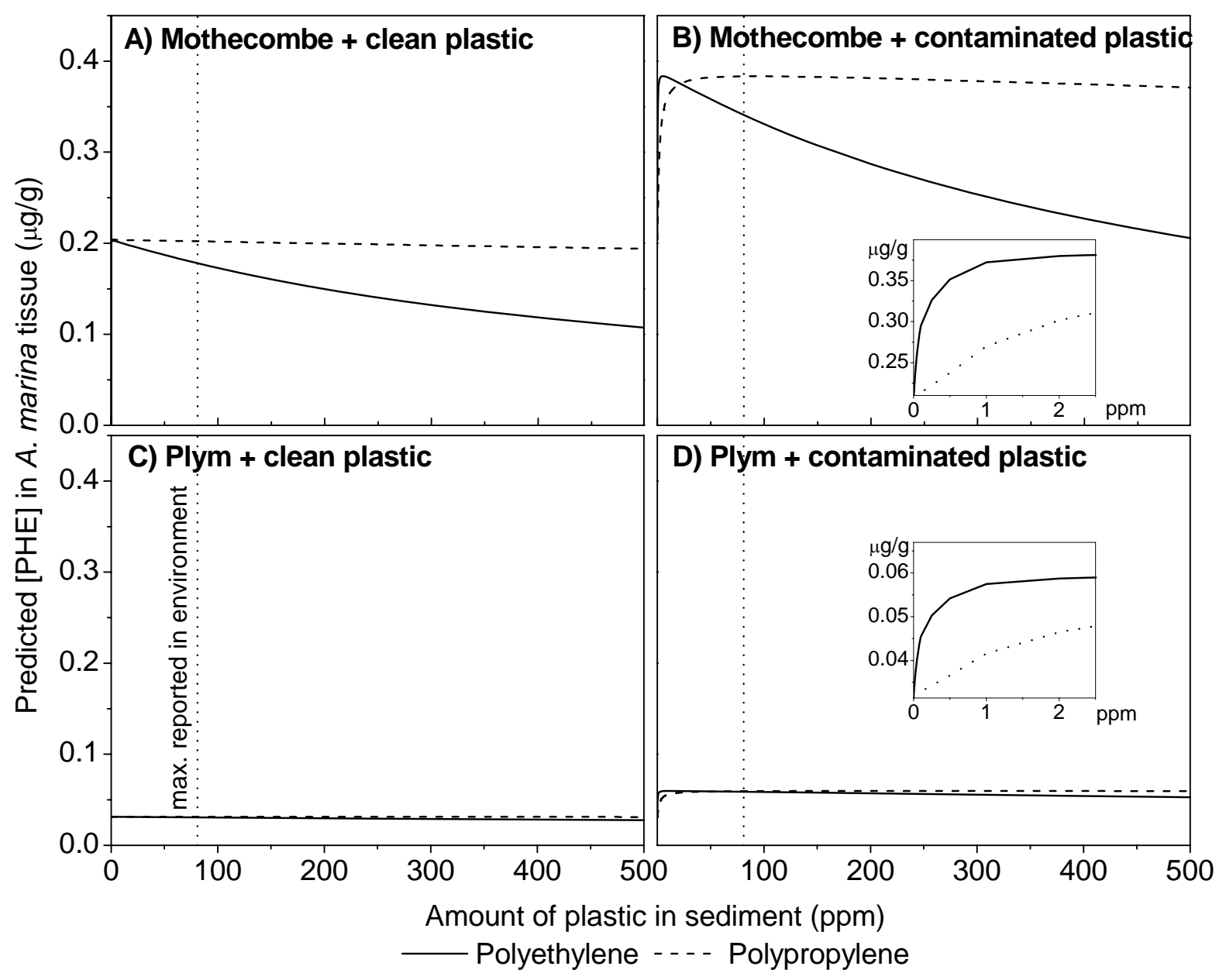

Figure S1. Predicted amount of phenanthrene accumulated in A. marina tissue from (A) Mothecombe (low \%OC) sediment with clean plastic (B) Mothecombe sediment with plastic contaminated in the SML (C) Plym (moderate \%OC) sediment with clean plastic 
(D) Plym sediment with plastic contaminated in the SML. An enrichment factor of 61 was used for the phenanthrene concentration in the SML compared to the bulk water [24]. Note that when $x=0$, the sediment contains no plastic.

Note: In Figure S1, maximum tissue concentrations are predicted at relatively low sedimentplastic concentrations $(\leq 150 \mathrm{ppm})$. At higher plastic concentrations (with fixed initial phenanthrene concentrations in the SML and in the porewater), the amount of phenanthrene predicted to accumulate in the worm is lower. This effect is more pronounced for polyethylene than for the other plastics studied. This can be explained by the ability of a small amount of plastic to sorb a vast amount of the finite quantity of phenanthrene in the SML. Once this plastic is introduced into the sediment, the presence of larger amounts of plastic "scavenge" the phenanthrene reducing the quantity available to the worm (and other phases), akin to the effect observed when clean plastic is added to the sediment. It should be noted that the equilibrium of phenanthrene between plastic and the SML is assumed to be independent of the benthic phenanthrene equilibrium between the sediment, porewater, plastic and A. marina lipids. 

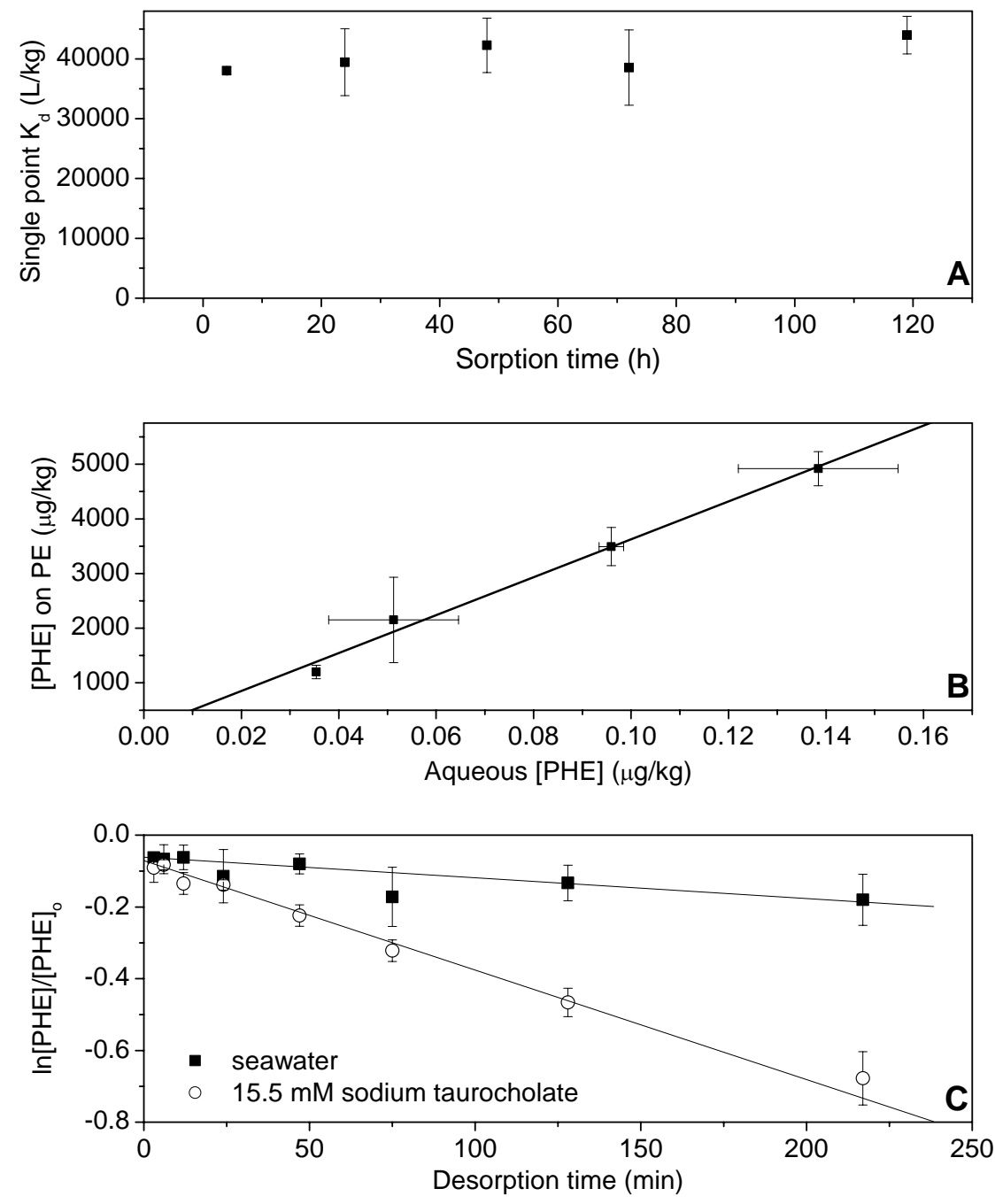

Figure S2. Sorption and desorption of phenanthrene to polyethylene: (A) Change in single point distribution coefficient $\left(K_{d}\right)$ with time $(B)$ Sorption isotherm $(C)$ Desorption kinetics in seawater (black squares) and in $15.5 \mathrm{mM}$ sodium taurocholate (open circles). Similar results were obtained for polypropylene and PVC. 
Modelling. A model system was developed to estimate the concentration of phenanthrene in A. marina, following exposure to a sediment-plastic mixture containing water contaminated with a low level of phenanthrene. Two scenarios were investigated: (1) the effect of adding clean plastic to sediment and (2) the effect of adding previously contaminated plastic to sediment. The equilibrium aqueous phase phenanthrene concentration $\left(C_{a q}\right)$ was calculated using a mass balance approach shown in equation S1. The identities of the parameters are listed in Table S1.

$C_{a q}=\frac{M_{P H E}}{\sum K_{d i} M_{i}+V_{a q}}$

An expanded version of this equation is shown in Equation S2. The distribution coefficient for the lipids was estimated from $K_{o w}$ using $K_{d, \text { lipid }}=3.2 \times K_{o w}^{0.91}[1]$.

$$
C_{a q}=\frac{M_{\left.P H E \_ \text {(water }\right)}+M_{\text {PHE_(plastic) }}}{K_{d_{-} \text {sediment }} M_{\text {sediment }}+K_{d_{-} \text {plastic }} M_{\text {plastic }}+3.2 K_{\text {ow }}{ }^{0.91} M_{\text {lipid }}+V_{a q}}
$$

Phenanthrene concentrations reported in the bulk water and the SML at Chesapeake Bay (USA) were used as a guideline for $M_{P H E}$ [2]. For scenarios employing clean plastic, $M_{P H E_{\text {_plastic }}}=0$. For simulations involving contaminated plastic, $M_{P H E_{-}(\text {plastic) }}$ was determined by allowing a prior equilibration of phenanthrene between the plastic and seawater in $10 \mathrm{~cm}^{2}$ of the sea surface microlayer ( $60 \mu \mathrm{m}$ thick), using Equation S3.

$$
M_{P H E_{-} \text {(plastic) }}=\frac{C_{S M L} V_{S M L}}{\frac{V_{S M L}}{K_{d_{-} \text {plastic }}}+M_{\text {plastic }}}
$$

The tissue concentration in A. marina was determined from $C_{a q}$, using Equation S4.

$$
C_{\text {worm }}=F_{\text {lipid }} 3.2 C_{a q} K_{o w}^{0.91}
$$


Table S1. Identities of parameters used in the model

\begin{tabular}{|c|c|c|c|}
\hline Parameter & Identity & Unit & Value $^{a}$ \\
\hline$C_{a q}$ & Equilibrium concentration in the bulk aqueous phase & $\mu g \mathrm{~L}^{-1}$ & Equation $\mathrm{S} 2$ \\
\hline$C_{S M L}$ & Initial concentration in the surface microlayer & $\mu \mathrm{g} \mathrm{L}^{-1}$ & 0.428 \\
\hline$C_{\text {worm }}$ & Equilibrium concentration in worm & & \\
\hline$F_{\text {lipid }}$ & Lipid fraction in worm & - & 0.05 \\
\hline$K_{d \_p l a s t i c}$ & Distribution coefficient for the plastic & $\mathrm{L} \mathrm{kg}^{-1}$ & Table 3 \\
\hline$K_{d \_ \text {sediment }}$ & Distribution coefficient for the sediment & $\mathrm{L} \mathrm{kg}^{-1}$ & Table 3 \\
\hline$K_{o w}$ & Octanol-water distribution coefficient for phenanthrene & - & $4.16 \times 10^{4}$ \\
\hline$M_{\text {lipid }}$ & Mass of lipids in the worm & $\mathrm{kg}$ & 0.00006 \\
\hline$M_{\text {plastic }}$ & Mass of plastic & $\mathrm{kg}$ & $1.5-M_{\text {sediment }}$ \\
\hline$M_{\text {sediment }}$ & Mass of sediment & $\mathrm{kg}$ & $1.5-M_{\text {plastic }}$ \\
\hline$M_{P H E_{-}(\text {water })}$ & Initial mass of phenanthrene in the water & $\mu \mathrm{g}$ & 0.0028 \\
\hline$M_{P H E \_(p l a s t i c)}$ & Initial mass of phenanthrene on the plastic before & $\mu \mathrm{g}$ & Equation S3 \\
\hline$V_{a q}$ & Volume of the aqueous phase & $\mathrm{L}$ & 0.4 \\
\hline$V_{S M L}$ & Volume of the surface microlayer & $\mathrm{L}$ & 0.006 \\
\hline
\end{tabular}

1. Schwarzenbach, R. P.; Gschwend, P. M.; Imboden, D. M., Environmental Organic Chemistry. 2nd ed.; Wiley: Hoboken, 2003.

2. Hardy, J. T.; Crecelius, E. A.; Antrim, L. D.; Keiesser, S. L.; Broadhurst, V. L.; Boehm, P. D.; Steinhauer, W. G.; Coogan, T. H., Aquatic surface microlayer contamination in Chesapeake Bay. Mar. Chem. 1990, 28, 333-351. 